\title{
Neuro-Immuno Psychology
}

\author{
Anil Thomas \\ NLP Master Practitioner \& \\ Gestalt Therapist \\ Mumbai, India
}

Ananya Ramesh

School of Allied Health Sciences,

Manipal University

Chennai, India

Psychoneuroimmunology, an evolving field, is made of three parts. Thoughts (psycho-) control the brain (neuro) which, in turn, influences the immune system (immunology). In this article, through demonstrations, research evidence, illustrations, and live examples, we will understand how our perception and beliefs of our environment actualize our body's ability to heal itself.

Keywords: Thoughts, Immune System, Perceptions, Beliefs.

\section{Neuro-Immuno Psychology}

Psychoneuroimmunology comprises the study of three main components, namely, psychological factors, neurological processes, and immunology. Psychological factors refer to thoughts and cognition, neurology to the brain and the nervous system, and immunology to the study of our immune system. It is a growing field that explores how psychological factors and neurological processes affect the functioning of our immune system (Dilts, n.d.). The immune system is a natural intelligence and healing system; it is the way our body corrects itself. Psychoneuroimmunology has its basis on the idea that psychological factors influence the functioning of various aspects of our nervous system, which consequently affects our immune system to some degree.

\footnotetext{
This research was done as a part of an Global Internship Research Program. GIRP is an Umang Foundation Trust initiative to encourage young adults across our globe to showcase their research skills in psychology and to present it in creative content expression.

Editing and reviewing credit : Aalia Passanha
}

We gratefully acknowledge the support of Mr. Anil Thomas for the mentorship and support.

Correspondence concerning this article should be addressed to E-mail: office@ijngp

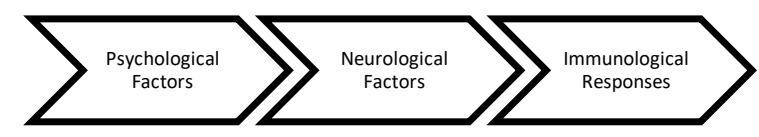

To put it simply, the invisible energy of thoughts can create feelings of external and internal biology. External biology includes body posture, orientation, behaviors, languages, attitudes, and the like. Internal biology consists of the hormones that get released by the endocrine system. Several physiological findings support the ideology of a direct relation between neurological reactions and immune system response. The thought that you think happens in the form of visual, auditory, kinesthetic, olfactory, and gustatory modalities, commonly referred to as VAKOG. This thought, in turn, creates chemicals in our body (feelings of external biology and internal biology). In this article, we mainly focus on our internal biology and the immune system. The immune system is an internal

Defense mechanism, a sort of internal security system, which continuously scans and searches the body for a foreign body to fight it. It not only fights the foreign body, but it also memorizes it so that it can fight the same even more effectively in the future. What this means is that the immune system can learn. However, if you invoke stress hormones, it suppresses the function of the immune system, thereby compromising the immune system. Before we elaborate on psychoneuroimmunology, it is essential to orient ourselves to three types of stress or injury. These include physical stress (e.g., accidents, falls, surgery, trauma), chemical stress 
(e.g., hangovers, blood sugar levels, hormones, foods), and emotional stress (e.g., family tragedies, job, finances, loss). All of these knock the body and brain out of balance.

\section{The Immune System}

People always believed that the immune system operated separately from other structures in the body. Supposedly, we consisted of body-mind and the immune system. Edward Blalock, in the early 1980s, made a breakthrough, challenging our existing idea of being composed of separate autonomous systems (Blalock, 1992). Lymphocytes (cells part of our immune system) produce interferons, which are peptides, and Blalock studied these interferons. His experiment involved putting lymphocytes in a petri dish and stimulating them to produce interferons. Interestingly, he discovered that the lymphocytes were making several other peptides, previously thought to be made only by endocrine glands (Blalock, 1992). This discovery implicated that each immune cell produced and received peptides: the molecules of information and emotion already found in the brain and other sites throughout the body. Many tried to discredit this information as it was so counter to the conventional model of the immune system. However, Pert and her co-workers straightaway began to explore this possibility, and eventually, there were many confirmations and expansions of Blalock's original work for it to be dismissed. Pert and her colleagues found that the immune system can send information to the brain via immunopeptides as well as receive information from the brain via neuropeptides (Pert, 1997). Their work confirmed Blalock's research by pointing undeniably to the presence of a chemical mechanism through which the immune system could communicate with the endocrine system and the nervous system, including the brain. Peptides, which regulate physiological functions, which are also associated with emotions, link a network which includes the immune system connecting with the rest of our body. This finding means that we can communicate with our immune system, as our immune system communicates with the rest of us.

\section{Research Findings Backing Psychoneuroimmunology}

Since the early 1980s, the field of psychoneuroimmunology has produced many breakthroughs. This statement is especially true as regards our knowledge of the interaction between the brain and the immune system. For example, we consider it common knowledge that stress and emotions change blood chemistry, thereby affecting the immune system and its functioning. With that said, immune cells display a capacity to respond directly to the same chemicals with which our brain and nerve cells communicate.

\section{Stress}

Stress hormones, such as corticosteroids, inhibit the immune system. Sometimes this is helpful. For example, after transplantation of new organs or tissues, corticosteroids are used to suppress the immune system so that it does not identify the new organ as a foreign body and reject it. However, most times, it is harmful. When the immune system is suppressed, the nervous system has to work extra hard to get the body back to homeostasis, and this is how it gets compromised. As per research findings, the pathway between "mind" and "body" can be hypothesized as a fivestep process (Dilts, n.d.):

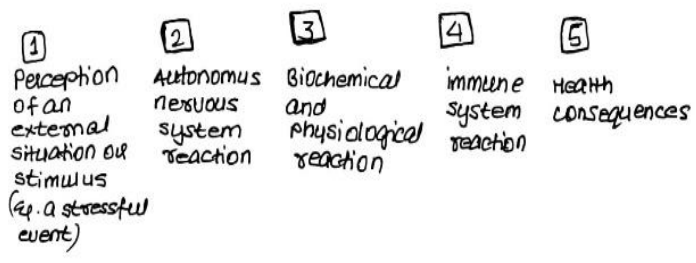

In one study, rats were given red-coloured, sweetly flavoured water (Ader \& Cohen, 1981). Initially, the researchers gave the rats water contaminated with a substance that suppressed the rats' immune responses. The researchers measured the time it took the rats to figure out that the water was causing their illness and stopped consuming it. The researchers then ceased to taint the water and measured the duration it took the rats to deem the water as being non toxic to drink. Well into the study, the researchers began to notice that several rats were dying at a very early age despite drinking perfectly safe water. However, when they measured the immune system functioning of the rats, they found that it was radically suppressed, especially after the rats drank the water. Through the process of conditioning, they were restraining their immune responses, to the point of their destruction. This experiment brings us to the question - How is it that some people can heal themselves faster, while some fall sick faster and some are stuck? The truth is that we are not at the mercy of something. We create these realities by choosing where to focus, by choosing which behaviours we are replicating continuously. A more detailed answer to this lies with Dr Bruce Lipton, a stem cell biologist and author as outlined below. 


\section{Genetic Activity}

People thought that genes were selfactualizing - genes could turn themselves on and off - until recently. Consequently, most people believe that their genes control their lives. Bruce Lipton's research introduces a radical new understanding of cell science. He found that we control our genome rather than being slaves to it (Lipton, 2005). It is now discerned that the environment, and more specifically, our perception of the environment directly controls our gene activity. This finding helps us understand why people can have spontaneous or radical remissions and recoveries from disabilities deemed permanent. This breakthrough forms the foundation in all healing because it recognizes that when we alter our perception or beliefs, we send entirely different messages to our cells, thereby reprogramming their expression. This new science is called epigenetics (Lipton, 2005). He eloquently speaks more about this in the documentary, "Heal" (Shomer, Morrisey, \& Noonan, 2017). He says biological organisms adapt their biology to fit into an environment. An example quoted by him involved the liver cells. He said they should be adjusting to what is going on in the environment. However, the liver cell is not touching the environment, so, how does it happen? He says that it depends on the nervous system to send information about the environment to our internal body so that the cells can adjust accordingly. Consciousness is an interpretation, so our mind is interpreting the environment. If we change our perception, our mind, change our belief about life, we change the signals entering and altering the function of the cell. By our ability to change the environment, and to change our perception of the environment, we can control our genetic activity. We are not a victim of our heredity, but a master of our genetic activity.

\section{Emotions}

Gregg Braden, a five-time New York Times best-selling author and scientist, spoke of this connection (Shomer, Morrisey, \& Noonan, 2017). He mentioned that when we have an emotion within our hearts, that emotion sends a signal to our brain. The quality of that signal determines what the brain does in response to the feeling. Take a cue from the heart to the brain that is a smooth series of waves: nice, even, coherent. The brain will match this level, even, organized chemistry, and it will release the chemistry that supports life in our body. This process determines how immune systems become strong; a super-immune response.

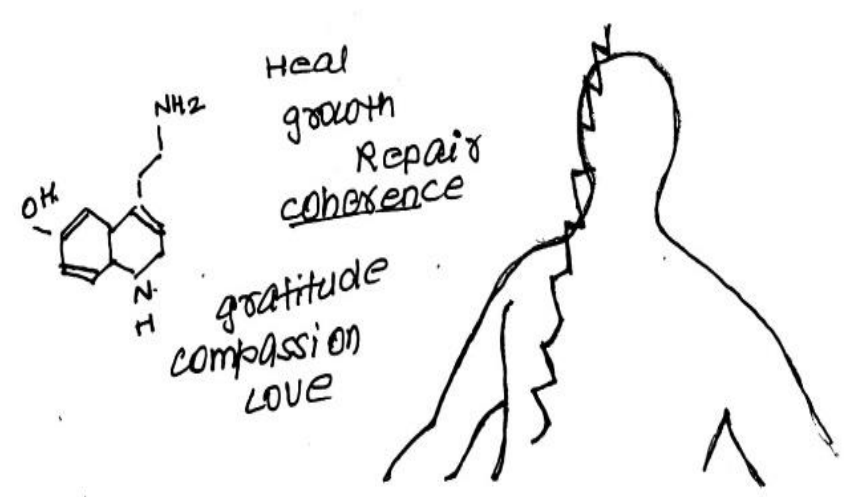

On the other hand, the stress chemistry when we feel frustrated, angry, jealous, or are afraid, produces a signal that looks kind of like a "bad day on the stock market." A lot of chaotic, jagged, unorganized waves going from the heart to the brain. The brain receives those waves and matches this stress chemistry.
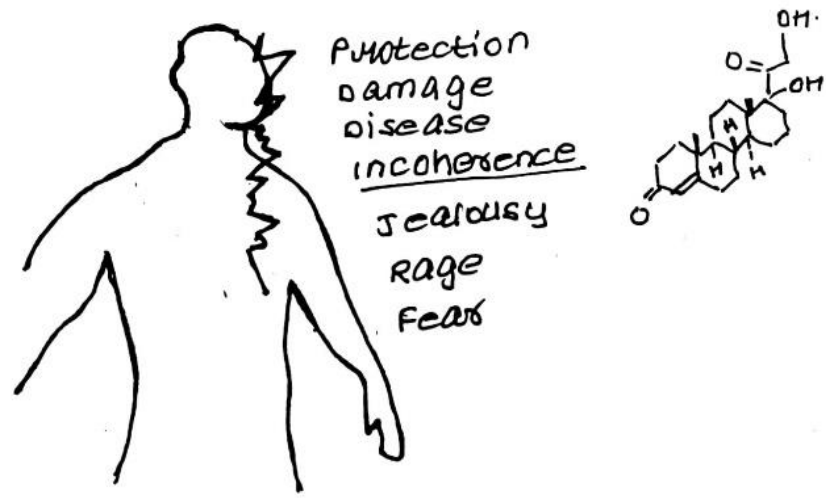

Along these lines, one research study (Pert, 1997) found many intriguing associations, such as one between cancer (wherein the immune system is unable to deal with potential cancer cells effectively) and the suppression of anger. They also found an association between susceptibility to heart attack and the overly aggressive personality; a relation between a high resistance to some viral infections and happiness. A particularly intriguing example given by Pert includes the speculation that we do not develop colds when we are eagerly anticipating something, such as skiing. This occurrence may happen because norepinephrine (an informational substance associated with a happy state of mind) blocks the receptors through which the rhinovirus (an infectious virus and a predominant cause of common colds) typically enters the cells. When we think about an unpleasant event from the past, it becomes a learned behaviour. The body is so used to that negative emotion that it becomes a trigger. Automatically, stress gets built up, which in turn compromises the nervous and immune systems. 


\section{Language of NLP}

\section{Reframing}

Reframing helps a person to adapt. It allows a person to conserve energy for activities that matter, and to keep an illness/adversity from becoming their identity (Blake, 2002). Instead, they reframe the event as just something else going on in their life along with other things. It is a potent tool, especially concerning health issues. If one wants to change their reality, they need to think about what they are thinking (metacognitive skill). People often define their biology in the past. They tend to forget that their body is in the present, devoid of the stress. In the past, they compromised their body, their immune system. By thinking about it today, they bring past trauma to the present, creating their biology based on the past. Why not make our biology from the future point of view? Why not define themselves by the vision of the future? The path to the future is not through the emotions of the past but the learnings of the past. When we look at previous happenings, we need to separate the feelings from the wisdom and look ahead. The latest neuroscience research has shown that we can change the way our brain functions with a thought (Pert, 1997). In her book, Pert makes several associations between her research, her colleagues' research, and holistic practices. She identifies that memories, with the associated emotions, can be 'frozen' within particular muscular configurations. This finding supports methods such as healing massage and bioenergetics. Nodal points, where there are concentrations of specific peptides and peptide receptors, appear to correspond to the traditional acupuncture points used in Chinese medicine. Conscious breathing, the techniques employed by both the yogi and the woman in labour, is extremely powerful. She claims that comprehensive data is showing that alterations in the rate and depth of breathing produce changes in the amount and variety of peptides that are released from the brain stem, and vice versa (Pert, 1997). Emotions are viewed as the connection between our conscious, subjective experience, and the complex regulatory processes within the body, "the nexus between matter and mind, going back and forth between the two and influencing both." (Pert, 1997).

\section{Coding experiences at logical levels}

We experience things differently. We perceive certain things as part of our environment, as our abilities, thoughts, beliefs, values, identity, or even, at a higher level, as our spiritual connectedness. The lower on this scale that the experiences are coded, the easier they are to handle.
When we start practising this, we understand that we begin to heal not despite the hurt, but in spite of such pain. When Hellen Keller was asked how she developed the braille despite being blind, she said that she created the braille because of her blindness. Dr Kelly Turner, PhD, a researcher, lecturer, and counsellor in the field of Integrative Oncology, mentioned an interesting thing in the documentary, "Heal" (Shomer, Morrisey, \& Noonan, 2017). She said that if you perceive people are coming to help you and hold you and you perceive this outpouring of love, they are already helping you through your healing process. Because if you sense that love, as soon as you believe it, you have an oxytocin response. This oxytocin response is associated with increased natural killer cells, increased white cells, and even the immune response gets heightened.

\section{Associated and dissociated memories}

While practising NLP, when the practitioner assists the clients to dissociate from a traumatic memory and view it from the standpoint of a third-party observer, changes begin to take place (Blake, 2002). The said client may have been engaging in self-critical talks, and therefore kicking their immune system out of balance. This criticism begins to reshape hence bringing change to the perception of power and responsibility. For example, a client having just gotten out of a romantic relationship may be feeling guilty and blaming themselves for the failure of the relationship. By making them dissociate from the situation and look at it from the perception of a sympathetic friend might be able to appreciate their efforts and understand that the shortcomings of the relationship did not have anything to do with their personality. This kind of a change in view can affect long-standing emotional patterns, thereby altering the peptide patterns flowing through the body from unhealthy to health-enhancing. The practitioner helps the clients seek out memories of experiences wherein the client was happy, in good health, experiencing high levels of well-being. By assisting the clients in anchoring fully into these memories ("see what you were seeing, hear what you were hearing, and be in the memory"), the practitioner encourages the production of peptides that can restore patterns of well-being associated with that time (Blake, 2002). This process will help lower the blood pressure, reduce the blood sugar levels, and bring the client to homeostasis in the example mentioned. 


\section{Representational systems and their sub modalities}

We perceive the environment through our five senses - VAKOG, as well as the internal dialogue (Auditory digital or Ad). Each representational system has a submodality. Working with submodalities can also be helpful - clients can be asked to represent good health in some ways, such as, with a clear focus. They may be asked to make it life-sized, in realistic colour, as a threedimensional moving picture, complete with sounds of what they would be like in a state of well-being, projected into wherever they see the future. This process can help shape their entire system into a movement toward that way of being. When you let all five senses participate without competing beliefs, you learn to unwire and rewire habits. You need to unwire old emotions and their corresponding trigger response. This involves forgetting memories of emotions stored in the body and recondition the body to new behaviours. That is how you pull out energy from past trauma and invest it in the future. When you successfully do this, you can look at past trauma and say, "Ah! I have learnt from that, I don't get the same old feelings and I am beginning to change that behaviour." Because what has happened has happened, what you had is gone, so the least you can do is take back the energy and emotions. This thought process will help you invest in the immune system better.

\section{Shifting the tonality of our internal dialogue}

We often have a self-critical internal dialogue. The usually suggested way of counteracting these is with affirmations. However, affirmations mostly don't work because we don't believe them! We bring in the emotions of our past. On the other hand, we believe the negative self-talk because we have heard them so often. When we keep these negative self-talks but start to play with their tonality, interesting things unravel. Try it now. Take a negative thought and say it out loud. Now say it softly, in a screechy tone, and make it fade in and out until it disappears, and maybe say it dramatically like opera singers. You would notice that this exercise would render the words meaningless and perhaps even ridiculous but would put a smile on our face.

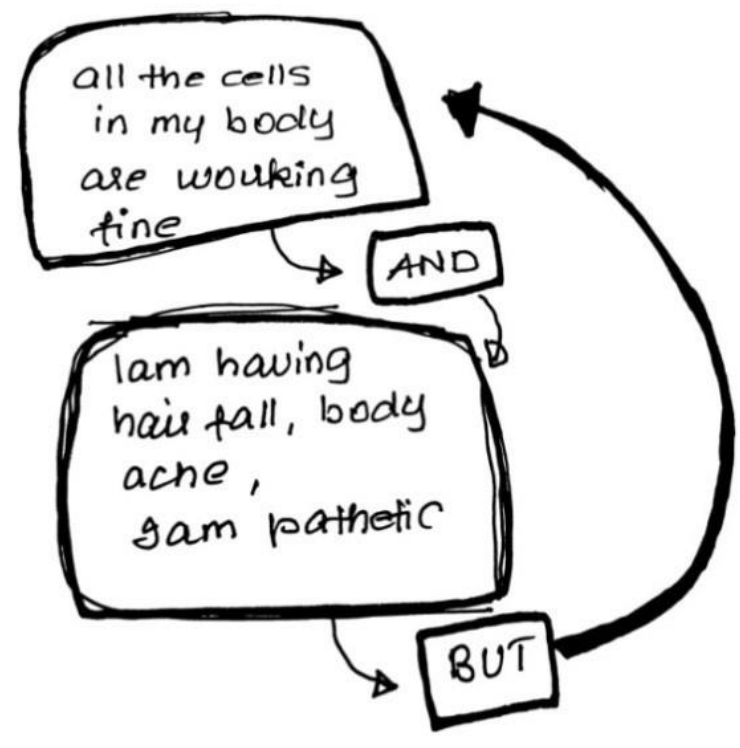

Generally, if you ask yourself or your clients to notice the feelings after singing this jingle, it is common for a reply such as, "but every little cell in my body is not okay. My hair is falling, my head hurts, and I have a backache. So, every cell is not okay." It is essential to understand that contradicting ideas can exist together. Yes, it is okay that all the cells are not working fine. For one to be true, the other need not be false.

When we hold two conflicting ideas together, we discover that there lies beauty in between. Keeping honesty with optimism, holding the brutal truth with the dream is nothing but bravery. When reality meets fantasy, creation and execution take place. It is important to note that the jingle is not about the words as much as it is about the rhythm and the action. Here, you involve three modalities. Imagine if you can apply all five senses at the same time. That is how you create magic.

Affirmations are vital as they are words or language, which can create emotions, which in turn make hormones. Even though words can elicit feelings, the latter is more important to pay attention to as they are the language of the body, while words are the language of the thought. 


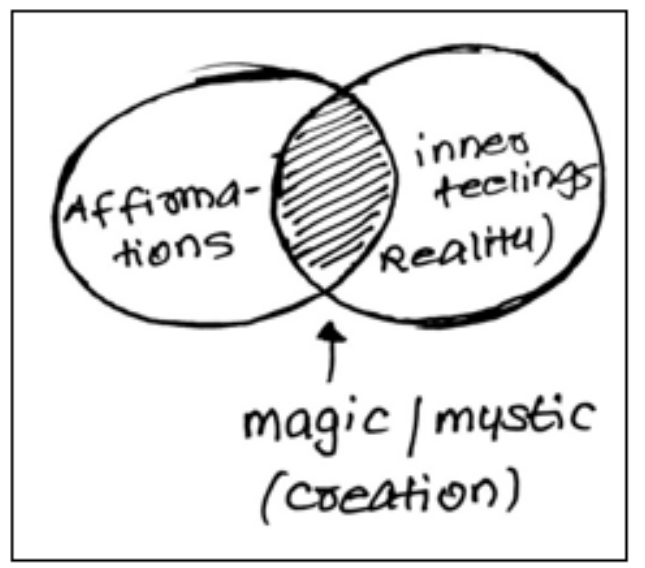

6. Pessimism and Optimism

These two states of mind affect our health. Joseph O'Connor and McDermott have outlined the pessimism and optimism strategies in their book NLP and Health (O'Connor \& Dermott, 1996). The pessimist takes a worthy and successful experience and views it as a rare accident for which the individual cannot take credit. He/she takes a bad experience and

a) Generalizes it ("this is what life is like"),

b) Internalizes it thereby blaming themselves ("this happened to me because of who I am")

c) Globalizes it ("this is the kind of thing that always happens to me").

On the other hand, an optimist views bad experiences as one-offs or isolated events caused mostly by external factors, and something from which they can learn. They believe that the universe around us is mostly a kind place; when they are successful, they see it as a result of their personality, and thus, can take credit for it.

Both good and bad things happen to everyone around us, including ourselves. It is imperative to keep in mind that there are factors within our control, while some are not. Whether we choose to view our world as an optimist or a pessimist is within our control, which in turn has an impact on how we move through life, and this consequently affects our mood-peptides-immune system.

NLP is about structure. Although prayers are critical, it is also vital to act as though your prayers have been answered. It is the trick to know that your prayers have been answered. If you are willing to fire the right optimism, the right thought, then you elicit the right feeling. This feeling evokes the right hormones, which in turn releases a more powerful army, the defence system of our body; the t-cells from the thymus and B cells from the bone marrow. This release of cells improves your stamina, core strength, inner strength, agility, and even flexibility. The future is not created yet, so one can work on making the future where they belong by focusing on every little cell - it is a conscious effort. Viktor Frankl, for example, did this for six years. He took the bowl of water with fish on top and said, "I am not going to give it my judgement, my condemnation, whereas I am going to provide it with my gratitude. He started viewing his world through this gratitude. It was a lie, but sometimes lies need to be told because they elicit a good feeling, like fairytales and Santa Claus.

\section{Techniques of NLP}

NLP has developed several techniques based on the discoveries of psychoneuroimmunology. The Allergy Process developed by Robert Dilts, for example, uses the disassociation and finding disputing examples to help change the response of the autonomic nervous system to allergy-triggering stimuli (Dilts, n.d.). This technique is found to recondition the immune response to the allergen.

Other NLP methods that influence the immune system include using visualization, submodalities, and affirmations for healing to ascertain a positive 'response expectancy'. Dr David Hamilton, $\mathrm{PhD}$, an organic chemist, gave an example in the documentary, "Heal" about visualization as a part of healing (Shomer, Morrisey, $\&$ Noonan, 2017). He mentioned that the underlying mechanism of the visualization process is that people take an internal picture of illness and convert it into an inner image of wellness. They do this over and over again. To quote the examples given by $\mathrm{Dr}$ David Hamilton: imagine a person getting chemotherapy. They imagine the chemo drugs as little piranha fish nibbling at the tumour. In their mind's eye, what they see is their tumour getting smaller and smaller until it is gone. Similarly, people in radiotherapy imagine the radiation like bolts of lightning going at the tumour, and the tumour getting smaller and smaller until it is vanquished.

NLP techniques such as Future Pacing, the New Behavior Generator, the Submodality Swish, Logical Level Alignment, and the Belief Installation Procedure help to increase outcome expectancy, and condition appropriate immune system reactions (Dilts, Halbom, \& Smith, 1990). These techniques function by aiding people to build a more prosperous, multi-sensory internal map of future actions and preferred states. 
Other NLP techniques help people to alter restrictive beliefs that suppress the immune system by creating stressful states or by producing "negative response expectancy" (similar to the rats that drank the red-coloured, sweet-flavoured water). Techniques such as Conflict Integration, Reimprinting, the Belief Change Cycle, Belief Outframing and Sleight of Mouth are all examples of processes which can influence immune system functioning by altering or updating beliefs (Dilts, Hlbom, \& Smith, 1990).

\section{Examples of Self-Healing}

\section{Milton H. Erickson}

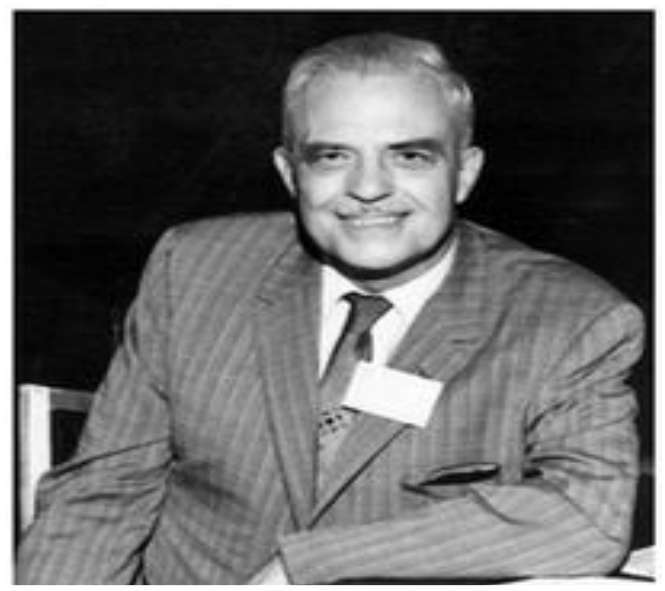

"I am very confident. I look confident. I act confident. I speak in a confident way.."

At the age of 17, Milton Erickson contracted polio and became severely paralyzed. Doctors were expecting the worst, and his mother was informed that he would not wake up the next morning. To everybody's surprise and what was deemed a miracle, Erickson made it the next day before slipping into a coma for three days.

Over time, however, his body began to heal. He regained the ability to speak and move his arms. He also developed the ability to walk with a cane (Hetelekides, 2018). He overcame this overwhelming physical adversity while lying in bed, by focusing on what he called "body memories."

Seemingly, by directing his conscious attention on these pseudo-subconscious memories of motor movements, Dr Erickson was able to almost entirely rebuild deliberate control to body parts (Hetelekides, 2018). Whether or not he knew why the cognitive act of concentrating on these "body memories" was helping him recover, it is importantly immaterial to his recuperation. However, for epistemological purposes, this information would help understand the underlying mechanisms at work in such a process.

We could relate this to Dr Bruce Lipton's work. Within our bodies at this very moment, there are billions of stem cells, embryonic cells intended to repair or replace damaged tissues and organs (Lipton, 2005). However, the activity and fate of these regenerative cells are epigenetically controlled. In other words, they are deeply influenced by our thoughts and perceptions about the environment. Hence, our beliefs about ageing can either interfere with or enhance stem cell function, causing our physiological regeneration or decline.

As opposed to Darwin's theory which emphasized competition and struggle, cooperation, and community, are the underlying principles of evolution, as well as the underlying principles of cell biology. The human body represents the cooperative effort of a community of fifty-trillion single cells. A community, by definition, is an organization of individuals committed to supporting a shared vision.

\section{Joe Dispenza}

Joe Dispenza met with an accident during a triathlon event, experiencing severe damage to his spinal vertebrae along with a host of neurological symptoms including severe pain, numbness, loss of sensation in his legs, and the like (Dispenza, 2014). His orthopedic surgeon conveyed to him that his only option was a major surgery, which involved transplantation of the Harrington rod. The surgeon also told him that with the surgery, he would have a slight chance to walk again, will experience some disability, and will have chronic pain for the rest of his life. Without the surgery, however, he would remain paralyzed forever. Dr Dispenza decided to go against the medical recommendation.

He believed that there's an intelligence, an invisible consciousness, within each of us that's the giver of life. At the time, he reasoned that if this intelligence existed and if it willfully, mindfully, and lovingly had such extraordinary abilities, maybe he could take his attention off his external environment and instead go within and connect with his internal environment. He decided on two things. First, every day he would put all his conscious attention on this intelligence within him and give it a plan with detailed orders. Then he would surrender his healing to this intelligence which he perceived has unlimited power. Second, he would not let any unpleasant thought slip by his awareness. 


\section{Neuro-Immuno Psychology}

Nine and a half weeks past the accident, he got up and walked back into his life and all without any cast or surgery. He fully recovered and even started seeing patients again at ten weeks. He trained and lifted weights again, while continuing his rehabilitation, at twelve weeks. He discovered that he was the placebo (Dispenza, 2014).

\section{Conclusion}

When our mind perceives the environment to be safe and supportive, the regenerative cells in our bodies focus on growth. Cells need a boost to maintain the body's healthy functioning. This mechanism is how the placebo effect works!

However, when we experience stress, our cells adopt a defensive protection stance. When that happens, the body's energy resources typically used to sustain growth get diverted to these protective systems. This diversion results in growth processes getting restricted or suspended, as the system is stressed.

The principal source of stress signals is the system's central voice - the mind. Analogically, the mind is like the driver of a vehicle. If we engage in good driving skills while managing our behaviours and regulating our emotions, then we can anticipate longevity, happiness and productivity. On the other hand, ineffective management of actions and emotions, like a terrible driver, stresses our body the cellular vehicle, hindering its performance and inciting a breakdown.

\section{References}

Ader, R. \& Cohen, N. (1981). Psychoneuroimmunology. New York, NY: Academic Press.

Blake, N. (2002, July). Psychoneuroimmunology and NLP. Positive Health. http://www.positivehealth.com/article/mindmatters/psychoneuroimmunology-and-nlp.

Blalock, J. E. (1992). Production of peptide hormones and neurotransmitters by the immune system. In: Blalock, J.E., (Ed.) Neuroimmunoendocrinology, 2nd rev. Chem. Immunol. Basel, Karger, 52, pp. 1-24. https://doi.org/10.1159/000319382

Dilts, R. (n.d.). Psychoneuroimmunology: Bolstering your immune system with nlp. http://www.nlpu.com/Articles/Psychoneuroimmu nology.htm.
Dilts, R., Halbom, T., \& Smith, S. (1990). Beliefs: Pathways to health and well-being. Metamorphous Press.

Dispenza, P. (2014). You are the placebo: Making your mind matter. Carlsbad, California: Hay House, Inc.

Hetelekides, E. (2018, December). The selfhealing potential of the unconscious mind [Blog post]. Houston Hypnosis Center. http://www.houstonhypnosis.com/hypnosisblog/self-healing-potential-unconscious-mind/.

Lipton, B. H. (2005). The biology of belief: Unleashing the power of consciousness, matter \& miracles. Mountain of Love/Elite Books.

O’Connor, J., \& McDermott, I. (1996). Principles of NLP. HarperCollins.

Pert, C. B. (1997). Molecules of emotion, why you feel the way you feel. London: Simon \& Schuster.

Shomer, A., \& Morrissey, R. (Producers), Noonan, K. (Director). (2017). Heal [Video file]. https://www.netflix.com/watch/80220013?trackI $\mathrm{d}=13752289 \& \mathrm{tct} x=0 \% 2 \mathrm{C} 0 \% 2 \mathrm{C} 0 \mathrm{ae} 1 \mathrm{~b} 51 \mathrm{~b} 53 \mathrm{fd} 07$ 07af73355b73ba101093ba49ca\%3Adadbb558d2 3ab40fe92dec062495bc8125df5aa2\%2C0ae1b51 b53fd0707af73355b73ba101093ba49ca\%3Adadb b558d23ab40fe92dec062495bc8125df5aa2\%2Cu nknown\%2C. 
